Citation: S. Farahani, R. Talebi, Mojdeh Maleki, R. Mehrabi, H. Kanouni (2021) Mating type distribution, genetic diversity and population structure of Ascochyta rabiei, the cause of Ascochyta blight of chickpea in western Iran. Phytopathologia Mediterranea 60(1): 3-11. doi: 10.36253/phyto-11616

Accepted: August 12, 2020

Published: May 15, 2021

Copyright: (c) 2021 S. Farahani, R. Talebi, Mojdeh Maleki, R. Mehrabi, H. Kanouni. This is an open access, peerreviewed article published by Firenze University Press (http://www.fupress. $\mathrm{com} / \mathrm{pm}$ ) and distributed under the terms of the Creative Commons Attribution License, which permits unrestricted use, distribution, and reproduction in any medium, provided the original author and source are credited.

Data Availability Statement: All relevant data are within the paper and its Supporting Information files.

Competing Interests: The Author(s) declare(s) no conflict of interest.

Editor: Diego Rubiales, Institute for Sustainable Agriculture, (CSIC), Cordoba, Spain.
Research Papers

\section{Mating type distribution, genetic diversity and population structure of Ascochyta rabiei, the cause of Ascochyta blight of chickpea in western Iran}

\author{
Somayeh FARAHANI ${ }^{1}$, RezA TALEBI ${ }^{2, *}$, Mojdeh MALEKI ${ }^{1, *}$, Rahim \\ MEHRABI $^{3}$, HOMAYOUN KANOUNI ${ }^{4}$ \\ ${ }^{1}$ Department of Plant Protection, Varamin-Pishva Branch, Islamic Azad University, Var- \\ amin, Iran \\ ${ }^{2}$ Department of Agronomy \& Plant Breeding, Sanandaj Branch, Islamic Azad University, \\ Sanandaj, Iran \\ ${ }^{3}$ Department of Biotechnology, College of Agriculture, Isfahan University of Technology, \\ Isfahan, Iran \\ ${ }^{4}$ Kordestan Agricultural and Natural Resources Research and Education Center, Agricul- \\ tural Research, Education and Extension Organization (AREEO), Sanandaj, Iran \\ *Corresponding author. E-mail: srtalebi@yahoo.com, mojdehmaleki@yahoo.com
}

Summary. Ascochyta blight (caused by Ascochyta rabiei) is an important disease of chickpea. Mating type distribution, genetic diversity and population structure A. rabiei isolates from western Iran, using specific matting type primers, and ISSR and SSR molecular markers. Two mating types were identified, with the $57 \%$ of isolates belonging to MAT11. Ten ISSR markers produced 78 polymorphic bands with an average polymorphism information content (PIC) value of 0.33 . Seven SSR markers showed high allelic variation (four to seven alleles) with the average PIC value of 0.61 . The generated dendrogram using neighbor joining approach with ISSR and SSR marker data grouped isolates in three clusters. Combined dendrogram and model-based population structure analysis divided the isolates into two distinct populations. No significant correlation was found between geographical origins of isolates and their genetic diversity patterns, although the isolates from North Kermanshah and Kurdistan were closely grouped, and most of isolates from Lorestan and Kermanshah were clustered in a separate group. This relative spatial correlation between geographical locations and A. rabiei grouping indicated high genetic diversity within populations and no significant gene flow between distinctly geographical regions. This suggests the nece0ssity of continuous monitoring of A. rabiei populations in order to design effective chickpea breeding strategies to control the disease.

Keywords. ISSR, SSR, population structure, Ascochyta blight, sexual reproduction.

\title{
INTRODUCTION
}

Chickpea (Cicer arietinum L.) is the third most important food legume, which provides human feed as a stable, rich and cheap source of vegetar- 
ian protein (Varshney et al., 2013). Chickpea originated from Middle-East, North Africa and Central Asia (van der Maesen, 1987; Talebi et al., 2008). Chickpea is produced in over 50 countries and India is the most important producer, with average yields of approx. $900 \mathrm{~kg} \mathrm{ha}^{-1}$. Iran ranks ninth in the world for chickpea production, with $2 \%$ of world production (Merga et al. 2019).

International chickpea seed yields are less than potential yield due to the narrow genetic base of most improved cultivars and uniform reaction to different abiotic and biotic stresses (Ghaffari et al., 2014). Ascochyta blight (AB), caused by Ascochyta rabiei (Pass.) Lab. (syn: Didymella rabiei Kov.), is one of the most important fungal diseases of chickpea. The disease may cause yield losses up to $100 \%$ under favourable cool and humid conditions (Ahmad et al., 2014; Farahani et al., 2019). In Western Iran (Kermanshah, Kurdistan and Ilam provinces) $A B$ is a serious damaging disease of chickpea, and in spring seasons (April to May), the disease is often severe (Nourollahi et al. 2011; Azizpour and Rouhrazi, 2017). Integrated strategies have to be applied to reduce $A B$, including agronomic practices (crop rotation and adjusting sowing date), application of fungicides and use of durably resistant chickpea cultivars (Kimurto et al., 2013; Vafaei et al., 2016; Farahani et al., 2019). Employment of resistant varieties has been considered the most effective, economic and environmentally-friendly strategy to manage the disease (Singh and Reddy, 1996; Varshney et al., 2009).

Both asexual and sexual reproduction has been reported for A. rabiei. The asexual stage occurs during the host growing season and the sexual stage develops on infected seed and crop residues during the winter (Trapero-Casas and Kaiser, 1992; Nourollahi et al., 2011). Sexual reproduction plays an important role in genetic diversity of fungal pathogens, which enable them to rapidly overcome host resistance genes as a response to selection pressure imposed by resistant cultivars (Chen and McDonald, 1996; Aghamiri et al., 2015). This variability of the pathogen led to breakdown of resistance in chickpea germplasm. Knowledge of pathogen diversity and mating type systems is fundamental for effective diseases management and breeding programmes (Varshney et al., 2009; Mehrabi et al., 2015; Baite and Dubey, 2018). However, field assessment of the genetic structure in A. rabiei populations may be not reliable due to lack of powerful discriminating tools and variable environmental condition. Measuring pathogen genetic diversity based on molecular markers at the DNA level can provide unbiased estimates of genetic variation which is independent of culture conditions (Nourollahi et al., 2011).
Different molecular methods, including SSR (Geistlinger et al., 2000; Phan et al., 2003b), AFLP (Varshney et al., 2009), RAPD (Santra et al., 2001), and mating-type specific markers (Phan et al., 2003a; Ozer et al., 2012), have been developed and utilized for genetic diversity assessment in A. rabiei populations from different countries, including Turkey (Bayraktar et al., 2007), Pakistan (Ali et al., 2012), India (Varshney et al., 2009) and other chickpea growing areas (reviewed by Pande et al., 2005). High levels of genetic and pathogenic diversity have also been reported in Iranian $A$. rabiei populations (Nourollahi et al., 2011; Azizpour and Rouhrazi, 2017). Biased mating type distribution has been reported in populations of this fungus collected from west and north-west Iran, that was dominated by the Mat1-1 mating type (Nourollahi et al., 2011; Azizpour and Rouhrazi, 2017). In Turkey and Tunisia, Mat1-2 has been reported as the dominant mating type (Rhaiem et al., 2007; Taylor and Ford, 2007). Previous studies on pathogenicity, genetic diversity using SSRs and Specific mating type DNA markers among Iranian isolates of $A$. rabiei have not been comprehensively described, and most previous Iranian studies were focused on a province or small geographical region (Younessi et al., 2004; Vafaei et al., 2016; Nourollahi et al., 2011; Azizpour and Rouhrazi, 2017).

The present study was undertaken to: (i) assess pathogenicity A. rabiei isolates collected from the west of Iran; (ii) assess genetic diversity of these isolates using SSR and ISSR markers; and (iii) characterize mating type distribution of Iranian A. rabiei isolates from different provinces using MAT-specific primers.

\section{MATERIALS AND METHODS}

\section{Ascochyta rabiei sampling and isolation}

Seventy-five A. rabiei isolates were collected from infected chickpea fields of western Iran provinces $(20$ isolates from Kurdistan, 46 from Kermanshah and nine from Lorestan) during the 2017 and 2018 growing seasons (Table 1). These provinces are geographically juxtaposed, but due to substantial mountains between them, their climatic conditions are different. Kurdistan has cold winters with mild summers and greater annual precipitation than the other two provinces. Samples were collected from 15 locations with minimum distance between the locations of $10-15 \mathrm{~km}$. At each location, samples were chosen every $20 \mathrm{~m}$ along a row from three to five parts of each infected field. Infected leaves were removed to a laboratory, were surface sterilized with sodium hypochlorite (0.5\%) for $2 \mathrm{~min}$, and washed twice 
Table 1. Numbers and mating types of 75 Ascochyta rabiei isolates collected from western Iran.

\begin{tabular}{lccccc}
\hline Province & $\begin{array}{c}\text { No. of } \\
\text { isolates }\end{array}$ & Mat1-1 & Mat1-2 & $X^{2^{*}}$ & $P$ \\
\hline Kermanshah & 46 & 30 & 16 & 4.26 & 0.039 \\
Kurdistan & 20 & 9 & 11 & 0.20 & 0.655 \\
Lorestan & 9 & 4 & 5 & 0.11 & 0.739 \\
Total & 75 & 43 & 32 & 1.61 & 0.204 \\
\hline
\end{tabular}

${ }^{*}$ Chi-square values were calculated under the null hypothesis of a 1:1 ratio of equal proportions of Mat1-1 and Mat1-2.

with sterilized distilled water. Samples were then plated onto CSMDA (40 g of chickpea seed meal, $20 \mathrm{~g}$ dextrose and $18 \mathrm{~g}$ agar in $1 \mathrm{~L}$ sterilized distilled water). Plates were incubated for 7 to $10 \mathrm{~d}$ at $20 / 22^{\circ} \mathrm{C}$. Single pycnidium isolates were obtained from the isolation plates, and were stored on CSMDA for pathogenicity tests.

\section{Pathogenicity tests}

Pathogenicity test for all isolates was carried out on the two susceptible chickpea cultivars 'Bivanij' (Iranian landrace susceptible check) and ILC1929 (International susceptible check) (Farahani et al. 2019). Purified single pycnidium A. rabiae isolates were grown in potato dextrose broth (PDB). The inoculum of each isolate was prepared in a water solution containing $0.20 \%$ of Tween 20 , and was adjusted to $6 \times 10^{5}$ conidia $\mathrm{mL}^{-1}$.

Two-week-old chickpea seedlings of the susceptible cultivars were inoculated with each isolate, and inoculated plants were kept in the dark under plastic bags for $24 \mathrm{~h}$. The plants were then transferred to a controlled greenhouse where environmental conditions were maintained at $23 / 18^{\circ} \mathrm{C}$ day/night, a $16 \mathrm{~h}$ photoperiod, and $\geq 85 \%$ relative humidity (Farahani et al., 2019). After 2 weeks, disease reactions on both cultivars were assessed using a 0-9 scale (Pande et al., 2011; Farahani et al. 2019). Plants that showed disease scores greater than 5 were considered susceptible to A. rabiae (Farahani et al., 2019).

\section{DNA extraction from isolates}

Single pycnidium A. rabiae isolates grown on CSMDA were each used to inoculate $50 \mathrm{~mL}$ PDB and then incubated at $20 / 22^{\circ} \mathrm{C}$ on an orbital shaker $(100 \mathrm{rpm}$ ) for $5 \mathrm{~d}$. Fungal biomass was harvested from each culture by filtration through Miracloth, was rinsed with distilled water, and then finely ground in liquid nitrogen. These preparations were then subjected to DNA extraction using the CTAB method (Weising et al., 1991).

\section{Mating type assay}

Mating types of all $75 \mathrm{~A}$. rabiei isolates was determined using the multiplex MAT-specific PCR assay (Barve et al., 2003). Primer combinations of SP21, Tail5 and Com1 were used in a single PCR reaction carried out in $20 \mu \mathrm{L}$ reaction volume, containing $1 \times$ PCR buffer, $25 \mathrm{ng}$ sample DNA, $2 \mu \mathrm{M}$ primer, $200 \mu \mathrm{M}$ of each dNTPs, $2.5 \mathrm{mM} \mathrm{MgCl}_{2}$ and 1.5 units of Taq DNA polymerase (Cinnagene). PCR amplifications were carried out in an Eppendorf thermocycler (Ali et al., 2012) as follows: initial denaturation at $95^{\circ} \mathrm{C}$ for 3 min followed by 35 cycles of $94^{\circ} \mathrm{C}$ for $20 \mathrm{~s}, 58^{\circ} \mathrm{C}$ for $20 \mathrm{~s}, 72^{\circ} \mathrm{C}$ for $40 \mathrm{~s}$, and a final extension at $72^{\circ} \mathrm{C}$ for $10 \mathrm{~min}$. PCR products were separated on $1.5 \%$ agarose gels, stained with ethidium bromide and visualized under UV light using a gel documentation system (Bio-Rad).

\section{ISSR analyses}

A set of 10 primers (UBC set, University of British Columbia, Canada) were used to determine genetic diversity of the A. rabiei isolates (Table 2). PCR reactions were each performed in $20 \mu \mathrm{L}$ reaction volume containing $1 \times$ PCR buffer, 30 ng sample DNA, $2.5 \mu \mathrm{M}$ primer, $200 \mu \mathrm{M}$ of each dNTPs, $2.5 \mathrm{mM} \mathrm{MgCl}_{2}$ and 1.5 units of Taq DNA polymerase (Cinnagene). PCR amplifications were carried out in an Eppendorf thermocycler (Germany), as follows: initial denaturation at $95^{\circ} \mathrm{C}$ for $2 \mathrm{~min}$, followed by 32 cycles of denaturation at $94^{\circ} \mathrm{C}$ for $30 \mathrm{~s}$, annealing at optimum $\mathrm{Ta}$ for $60 \mathrm{~s}$, and extension at $72^{\circ} \mathrm{C}$ for $90 \mathrm{~s}$. A final extension cycle at $72^{\circ} \mathrm{C}$ for $10 \mathrm{~min}$ followed. PCR products were separated on $1.5 \%$ agarose gels, stained with ethidium bromide and visualized under UV light using a gel documentation system (Bio-Rad).

\section{SSR analysis}

A set of seven SSR markers (Supplementary Table S1), previously described by Geistlinger et al. (2000) and Hayden et al. (2008), was used to determine the genetic diversity of the $75 \mathrm{~A}$. rabiei isolates. PCR reactions were each performed in $20 \mu \mathrm{L}$ reaction volume containing $1 \times$ PCR buffer, $15 \mathrm{ng}$ sample DNA, $2 \mu \mathrm{M}$ primer, $200 \mu \mathrm{M}$ of each dNTP, $2.5 \mathrm{mM} \mathrm{MgCl}_{2}$ and 1.5 units of Taq DNA polymerase (Cinnagene). PCR amplifications were carried out using an Eppendorf thermo cycler (Varshney 
et al., 2009) as follows: initial denaturation at $95^{\circ} \mathrm{C}$ for $2 \mathrm{~min}$, followed by 35 cycles of $94^{\circ} \mathrm{C}$ for $20 \mathrm{~s}, 53^{\circ} \mathrm{C}$ for $30 \mathrm{~s}, 67^{\circ} \mathrm{C}$ for $30 \mathrm{~s}$. PCR products were separated on $3 \%$ metaphor agarose gels, stained with ethidium bromide and visualized under UV light using a gel documentation system (Bio-Rad).

\section{Data analyses}

DNA bands obtained with ISSR primers were scored visually for the presence (1) or absence (0) of bands for all the A. rabiei isolates. Frequencies of incidence of all polymorphic alleles for each SSR marker were calculated and used for determining statistical parameters. Each band identified as an allele and scored as 'a', 'b', etc., from largest to smallest sized band. Number of alleles $(\mathrm{Na})$, effective number of alleles $(\mathrm{Ne})$, heterozygosity $(\mu \mathrm{e})$, Shannon-index (I) and polymorphism information content (PIC) were calculated for ISSR and SSR markers using GENALEX 6.1 software (Peakall and Smouse 2006). Marker indices (MI) were obtained by multiplying the average PIC with the effective multiplex ratio. Cluster analysis was conducted on the basis of a neighbor joining $(\mathrm{NJ})$ tree using dissimilarity matrix using DARwin 5.0.128 (Perrier et al., 2003). For the analysis of population structure, a Bayesian model-based analysis was performed using STRUCTURE 2.1 software (Pritchard et al., 2000). A Monte Carlo Markov chain method was used to estimate allele frequencies in each of the $\mathrm{K}$ populations and the degree of admixture for each individual plant. The number of clusters was inferred using five independent simultaneous runs with 10,000 replications, using the admixture model and correlated allele frequencies with the $\mathrm{K}$ value ranging from 1 to 10 .

\section{RESULTS}

\section{Pathogenicity tests and mating type distribution}

Initially, the pathogenicity of $75 \mathrm{~A}$. rabiei isolates was confirmed on two susceptible genotypes. Prominent morphological differences were not seen between isolates. Both chickpea genotypes showed high susceptibility to all the isolates. Symptoms of Ascochyta blight appeared on the Iranian susceptible landrace, Bivanij 2-4 d earlier than on ILC1929 (Supplementary Table S2).

The multiplex PCR using the mating type primers amplified two amplicons (490 bp for Mat1-2 and 700 bp for Mat1-1), across the 75 A. rabiei isolates collected from three major chickpea growing provinces (Table 1; Supplementary Figure 1). Both mating types were found in isolates collected from different provinces. Isolates from Kurdistan and Lorestan showed equal distribution for both mating types, while isolates from Kermanshah had different proportions $(P=0.039)$ of the two mating types. This may have resulted from the low number of collected isolates from the other provinces or the geographical differences of the collection sites. Overall, 57\% of the isolates were the MAT1-1 mating type and $43 \%$ were Mat1-2, but the mating type ratio was not significantly different $(P=0.204)$ from 50:50 (Table 1 ).

\section{ISSR markers diversity analysis}

The ISSR markers revealed clear and scorable bands per primer for all the studied isolates (Supplementary Figure 1). Ten ISSR markers amplified 78 polymorphic bands with an average of 7.8 bands per primer (Table 2). The maximum number of polymorphic bands was obtained using UBC807 (ten bands) and the minimum

Table 2. Numbers of polymorphic bands (NPB), heterozygosity ( $\mu$ e), Shannon indices, polymorphism information content (PIC), and marker indices (MI) of ISSR markers used for defining genetic diversity of 75 Ascochyta rabiei isolates.

\begin{tabular}{|c|c|c|c|c|c|c|}
\hline Primer & Sequence & NPB & $\mu \mathrm{e}$ & Shannon Index (I) & PIC & MI \\
\hline UBC807 & AGAGAGAGAGAGAGAGT & 10 & 0.48 & 0.58 & 0.42 & 4.2 \\
\hline UBC815 & СТСТСТСТСТСТСТСТG & 8 & 0.38 & 0.47 & 0.38 & 3.04 \\
\hline UBC818 & CACACACACACACACAG & 8 & 0.36 & 0.46 & 0.37 & 2.96 \\
\hline UBC857 & ACACACACACACACACYG & 7 & 0.33 & 0.43 & 0.34 & 2.72 \\
\hline UBC822 & ТСТСТСТСТСТСТСТСА & 9 & 0.42 & 0.51 & 0.32 & 2.88 \\
\hline UBC860 & TGTGTGTGTGTGTGTGRA & 8 & 0.31 & 0.49 & 0.31 & 2.48 \\
\hline UBC864 & ATG ATG ATG ATG ATG ATG & 6 & 0.29 & 0.37 & 0.29 & 1.74 \\
\hline UBC880 & GGAGAGGAGAGGAGA & 7 & 0.30 & 0.39 & 0.29 & 2.03 \\
\hline UBC895 & AGAGTTGGTAGCTCT TGA TC & 8 & 0.28 & 0.42 & 0.32 & 2.56 \\
\hline UBC899 & CAT GGT GTT GGT CAT TGT TCC A & 7 & 0.28 & 0.34 & 0.28 & 1.96 \\
\hline Mean & & 7.8 & 0.34 & 0.44 & 0.33 & 2.65 \\
\hline
\end{tabular}


number using UBC864 (six bands). The PIC values for the ISSR primers ranged from 0.28 to 0.42 , with an average of 0.33 per primer. The marker index (MI) of the primers ranged from 1.74 (UBC864) to 4.2 (UBC807) (Table 2). At the population level the average of Shannon-index was 0.44 and heterozygosity ( $\mu \mathrm{e})$ was 0.34 . Cluster analysis using ISSR markers grouped the $A$. rabiei isolates into three distinct clusters (Supplementary Figure 2). Cluster I consisted of nine isolates, all collected from Kermanshah. Cluster II comprised 30 isolates that divided into two sub-clusters, and all isolates from Lorestan province grouped closely along with a few isolates from Kermanshah grouped in first sub-cluster. Cluster III contained 36 isolates and divided into two sub-clusters. All isolates in Cluster III originated from Kermanshah and Kurdistan provinces, while all isolates from Kurdistan grouped in a second sub-cluster (Supplementary Figure 2).

\section{SSR markers diversity analysis}

Seven SSR loci were used for genetic diversity analysis in the $75 \mathrm{~A}$. rabiei isolates, and these showed clear and scorable amplicons (Supplementary Figure 1). The SSR loci analyzed produced 38 alleles with an average of 5.42 alleles per marker. The numbers of alleles ranged from 4 to 7 , where the maximum number of alleles was observed in ArH05T and ArH06T (Table 3). The numbers of effective alleles ranged from 4.28 (ArH06T) to 1.97 (ArR01T) with an average value of 3. PIC ranged from 0.48 (ArR01T) to 0.76 (ArH06T) with an average of 0.61. The Shannon's information index (I) ranged from 1.06 (ArA06D) to 2.17 (ArH06T) (Table 3). Gene diversity $(\mu \mathrm{e})$ ranged from 0.56 to 0.84 with a mean of 0.69 . Genetic relationships between the $A$. rabiei isolates based on polymorphic bands from seven SSR markers grouped

Table 3. Numbers of alleles $(\mathrm{Na})$ and effective alleles $(\mathrm{Ne})$, heterozygosity $(\mu \mathrm{e})$, Shannon indices, polymorphism information content (PIC), and marker indices (MI) of SSR markers used for determining genetic diversity of 75 Ascochyta rabiei isolates.

\begin{tabular}{lcccccc}
\hline SSR locus & $\mathrm{Na}$ & $\mathrm{Ne}$ & $\mu \mathrm{e}$ & $\begin{array}{c}\text { Shannon } \\
\text { index }(\mathrm{I})\end{array}$ & $\mathrm{PIC}$ & $\mathrm{MI}$ \\
\hline ArH02T & 6 & 3.07 & 0.72 & 1.68 & 0.63 & 3.78 \\
ArH05T & 7 & 4.17 & 0.81 & 2.11 & 0.73 & 5.11 \\
ArH06T & 7 & 4.28 & 0.84 & 2.17 & 0.76 & 5.32 \\
ArR12D & 5 & 2.79 & 0.69 & 1.47 & 0.59 & 2.95 \\
ArA03T & 5 & 2.68 & 0.63 & 1.39 & 0.56 & 2.80 \\
ArR01T & 4 & 1.97 & 0.56 & 1.11 & 0.48 & 1.92 \\
ArA06D & 4 & 2.10 & 0.59 & 1.06 & 0.52 & 2.08 \\
\hline Mean & 5.43 & 3.01 & 0.69 & 1.57 & 0.61 & 3.42 \\
\hline
\end{tabular}

the isolates into three major clusters (Supplementary Figure 3). Cluster I contained seven isolates that all originated from Kermanshah province. Cluster II comprised 39 isolates divided into two sub-clusters. One sub-cluster contained seven isolates from Kurdistan and the other contained isolates from different regions. Cluster III comprised 29 isolates in two sub-clusters. In this cluster, isolates from Kurdistan and Kermanshah showed distinct patterns from isolates collected from Lorestan province.

\section{Genetic structure of Ascochyta rabiei isolates}

The general dendrogram (Figure 1) that was constructed using the combined data of all molecular markers (ISSRs and SSRs) grouped the A. rabiei isolates in two major clusters. Cluster I comprised isolates mostly collected from Kurdistan, and few isolates from north Kermanshah and Lorestan. Cluster II divided into two sub-clusters, one with all isolates originating in Kermanshah, and the other with isolates from Kermanshah, Lorestan and three from Kurdistan. The NJ-cluster analysis showed no relationships with geographical origin, but most isolates in cluster I were from closely associated regions (Kurdistan and North Kermanshah), except for two isolates from Lorestan.

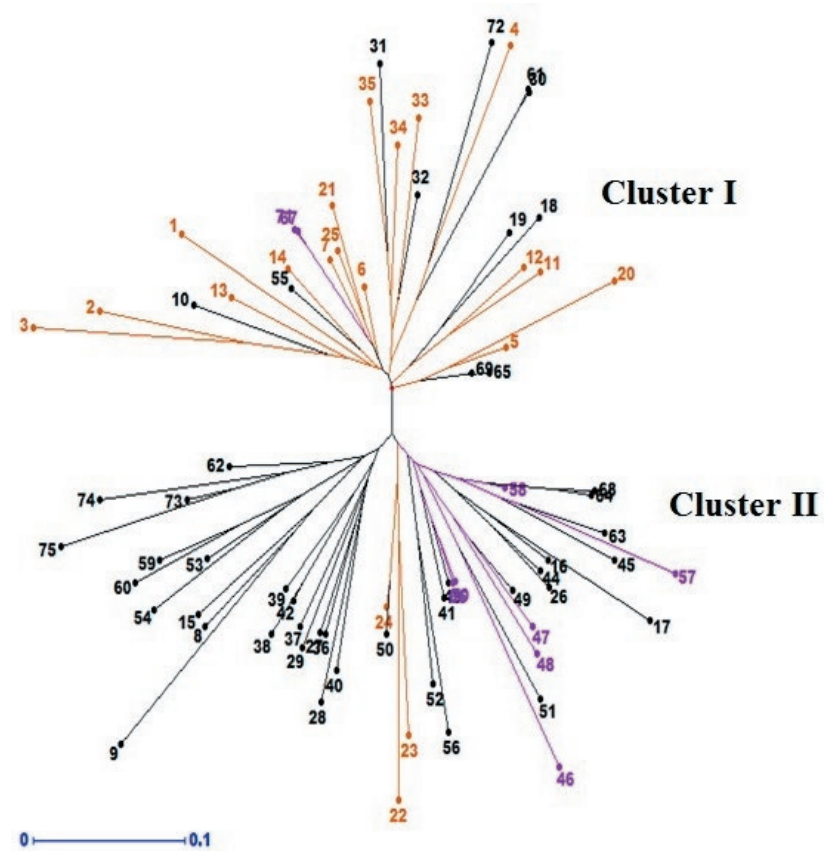

Figure 1. Neighbor joining (NJ) phylogenetic tree from pooled ISSR and SSR molecular data for 75 Ascochyta rabiei isolates collected from the western Iran provinces of Kermanshah (black), Kurdistan (red) and Lorestan (blue). 


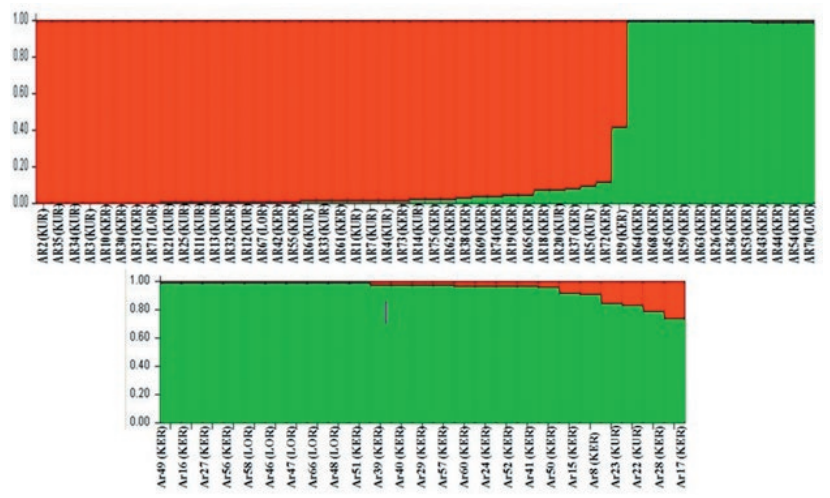

Figure 2. Membership coefficients estimated for Ascochyta rabiei isolates, determined from the greatest a posteriori likelihood using analysis with STRUCTURE and based on SSR and ISSR markers. The different isolates are represented by individual vertical bars divided into two colored segments (red and green) corresponding to the fraction of membership determined in Populations 1 and 2. The isolates are classified by province; Kermanshah (KER), Kurdis$\tan$ (KUR) or Lorestan (LOR).

The genetic structure of the $75 \mathrm{~A}$. rabiei isolates was further explored using the Bayesian clustering model implemented with the STRUCTURE software. This showed the greatest $K$ value of 2 , indicating the presence of two major clusters (Figure 2). The first population (Figure 2, indicated in red) comprised isolates from Kermanshah and Kurdistan, and two isolates (Ar67 and Ar71) from Lorestan. The second population (Figure 2, in green) included isolates from Kermanshah and Lorestan, and some isolates from Kurdistan. These results match those obtained from the NJ analysis (above), without significant correlation of isolate origin and population grouping.

\section{DISCUSSION}

Chickpea as cool season crops is mainly cultivated in many semi-arid areas, and seed yields and quality are reduced by major abiotic and biotic stresses (Kanouni et al., 2011; Karami et al., 2015). Ascochyta blight, caused by A. rabiei, is one of the most important fungal diseases of chickpea causing yield losses up to $100 \%$ in favourable cool and humid climates (Ahmad et al., 2014; Farahani et al., 2019). Variable pathogenicity and genetic structure in Iranian A. rabiei populations has been reported previously (Nourollahi et al., 2011; Azizpour and Rouhrazi, 2017; Farahani et al., 2019). Different factors, including sexual recombination, mutation, gene flow, migration, and selection pressure play important roles in population diversity of fungal pathogens
(McDonald, 1997; Aghamiri et al., 2015). This can lead to breakdown of host resistance in commercial cultivars (McDonald and Linde, 2002; Rhaiem et al., 2007; Peever et al., 2004; Ali et al., 2012). Characterization of genetic diversity and population structure of fungal populations in disease epidemic areas is fundamentally important for effective disease management, farming practices and design of crop breeding strategies (Azizpour and Rouhrazi, 2017).

The present study was conducted to the define population structure of Iranian A. rabiei isolates, through outline of aggressiveness patterns, mating types and molecular marker diversity in isolates of this pathogen collected from three major chickpea growing areas of western Iran. All the assessed isolates showed high aggressiveness in pathogenicity tests. Two identified mating types had similar distributions, except for isolates those collected from Kermanshah province, where Mat1-1 was dominant. Nourollahi et al. (2011) showed that majorities (64\%) of Iranian isolates collected from two provinces in western Iran were of Mat1-1, but within populations the proportions of each mating type were close to $50 \%$.

Previous studies have showed biased distribution for A. rabiei mating types Mat1-1 in Tunisia and MAT1-2 in Turkey (Taylor and Ford, 2007; Rhaiem et al., 2007). Fungi can reproduce in different ways through sexual, asexual or mixed mating systems (McDonald and Linde, 2002). Mixed mating types provide greater capability for overcoming resistance genes in crop resources (McDonald and Linde, 2002; Rhaiem et al., 2007). In fungi, different mating types may be related to pathogenicity and fitness (Zhan et al., 2002; Phan et al., 2003a). However this is remains a question for Iranian populations of the pathogen, as the present study did not show relationship between aggressiveness and mating types in the A. rabiei population examined. These results indicate random sexual propagation of $A$. rabiei populations in Iran, has been reported in neighboring countries such as Turkey and Syria (Turkkan and Dolar, 2009; Atik et al., 2011).

Genetic diversity and population structure of $75 \mathrm{~A}$. rabiei isolates were analyzed using ten ISSR and seven SSR markers. Both marker types showed high genetic diversity in the A. rabiei isolates. The polymorphism of SSR markers showed 4 to 7 alleles with an average 5.42 alleles per locus. In contrast, Nourollahi et al. (2011) and Barve et al. (2004) reported greater allelic variation in $A$. rabiei populations, which was likely due to the greater number and geographic diversity of isolates used in their studies. The average PIC values in the present study for ISSR markers was 0.33, and for SSR markers was 0.61. The high Shannon diversity index (I) and heterozygo- 
sity (gene diversity) of SSR markers also indicated the diverse nature of the collected $A$. rabiei isolates.

NJ-cluster analysis using ISSR and SSR markers grouped A. rabiei isolates into three distinct clusters. The molecular data of ISSRs and SSRs were combined, to give the best interpretation of genetic diversity of the isolates examined, which grouped the isolates in two distinct clusters. The Kurdistan climate is Mediterranean, with cold winters, where most chickpea crops are sown in spring (February to March). These contrasts with south Kermanshah and Lorestan, which have a relatively warm climate with moderate winters, and where chickpea crops are mostly sown in autumn (November to December). These differences in chickpea growth conditions may influence the nature of $A$. rabiei isolates and their evolutionary processes. All A. rabiei isolates in this study showed high levels of pathogenicity and no significant relationships were detected between pathogenicity of isolates and collection sites.

Knowledge about pathogen genetic diversity and pathogenicity in different geographical areas can help plant breeders, to assist characterization of susceptible/resistant host germplasm against important diseases in chickpea, and for Ascochyta blight in particular (Farahani et al., 2019; Montakhabi et al., 2020). Results from the present study showed no correlation between A. rabiei isolate origin and genetic diversity pattern, although most of isolates collected from north Kermanshah and Kurdistan closely grouped in one cluster, and those collected from Lorestan and south Kermanshah grouped in another. This spatial relationship between geographical diversity and $A$. rabiei grouping indicated high genetic diversity within populations and no significant gene flow between distinctly geographical regions. Previous reports have indicated that some A. rabiei isolates from distinct continents grouped together, reflecting possible intercontinental migration by movement of pathogens through infected plants carried by seed exchange or agricultural vehicles (Kaiser, 1997; Nourollahi et al., 2011). Iran, Turkey and India are the main centres of origins for chickpea domestication and their fungal pathogens (van der Maesen, 1987; Talebi et al., 2008). The high genetic diversity of $A$. rabiei isolates detected in the present study supports the hypothesis that during long domestication and evolution of chickpea and $A$. rabiei in this area, genetic drift probably occurred. Distinct A. rabiei populations from Iran, Turkey and India indicate that pathogen migration rarely occurred, from closely-associated regions (Varsheny et al., 2009; Nourollahi et al., 2011). Abundance of asexual over sexual reproduction occurs in local populations (Morjane et al., 1994; Keller et al., 1997; Aghamiri et al.,
2015). Although, limited numbers of A. rabiei isolates were analyzed in this study, the present results showed high genetic diversity in isolates collected from different provinces. This study has given a basis for future strategies for breeding programmes and farming practices. Genetic variability and sexual recombination within populations may both increase the risks of increasingly diverse isolates that may overcome resistance in Iranian chickpea germplasm, and also enhance fungicide resistance in A. rabiei populations (McDonald and Linde, 2002; Varshney et al., 2009).

In conclusion, the present results have shown interesting aspects of $A$. rabiei populations co-evolved with chickpea in their domestication origins or more probably linked to climate condition associated with differences in cropping seasons. In addition, the necessity of designing appropriate breeding strategies for chickpea improvement in each region is emphasized, due to the host and pathogen genetic differences within specific populations.

\section{ACKNOWLEDGEMENT}

The authors thank Dr Mohammad Kazem Montakhabi (Iranian Plant Pathology Institute) for assistance with field sampling and for providing isolates for this study.

\section{LITERATURE CITED}

Aghamiri A., Mehrabi R., Talebi R., 2015. Genetic diversity of Pyrenophera tritici-repentis isolates, the causal agent of wheat tan spot disease from Northern Iran. Iranian Journal of Biotechnology 13(2): e1118.

Ahmad S., Khan M.A., Sahi S.T., Ahmad R., 2014. Identification of resistant sources in chickpea against chickpea blight disease. Archive of Phytopathology and Plant Protection 47(15): 1885-1892.

Ali H., Alam S.S., Attanayake R.N., Rahman M., Chen W., 2012. Population structure and mating type distribution of the chickpea blight pathogen Ascochyta rabiei from Pakistan and the United states. Journal of Plant Pathology 94: 99-108.

Atik O., Baum M., El-Ahmed S., Ahmed M.M., Abang M.M., ...Hamwieh A., 2011. Chickpea Ascochyta blight: Disease status and pathogen mating type distribution in Syria. Journal of Phytopathology 159: 43-449.

Azizpour N., Rouhrazi K., 2017. Assessment of genetic diversity of Iranian Ascochyta rabiei isolates using 
rep-PCR markers. Journal of Phytopathology 165 (7-8): 508-514.

Baite M.S., Dubey S.C., 2018. Pathogenic variability of Ascochyta rabiei causing blight of chickpea in India. Physiological and Molecular Plant Pathology 102: 122-127.

Barve M. P., Arie T., Salimath S.S., Muehlbauer F.J., Peever T.L., 2003. Cloning and characterization of the mating type (MAT) locus from Ascochyta rabiei (teleomorph: Didymella rabiei) and a MAT phylogeny of legume-associated Ascochyta spp. Fungal Genetics and Biology 39: 151-167.

Barve M.P., Santra D.K., Ranjekar P.K., Gupta V.S., 2004. Genetic diversity analysis of a world-wide collection of Ascochyta rabiei isolates using sequence tagged microsatellite markers. World Journal of Microbiology \& Biotechnology 20: 735-741.

Bayraktar H., Dolar F.S., Tor M., 2007. Determination of genetic diversity within Ascochyta rabiei (Pass.) Labr., the cause of Ascochyta blight of chickpea in Turkey. Journal of Plant Pathology 89: 341-347.

Chen R.S., McDonald B.A., 1996. Sexual reproduction plays a major role in the genetic structure of populations of the fungus Mycosphaerella graminicola. Genetics 142(4): 1119-1127.

Farahani S., Talebi R., Maleki M., Mehrabi R., Kanouni H., 2019. Pathogenic diversity of Ascochyta rabiei isolates and identification of resistance sources in core collection of chickpea germplasm. Plant Pathology Journal 35(4): 321-329.

Geistlinger J., Weising K., Winte, P., Kahl G., 2000. Locus specific microsatellite markers for the fungal chickpea pathogen Didymella rabiei (anamorph) Ascochyta rabiei. Molecular Ecology 9: 1939-1941.

Ghaffari P., Talebi R., Keshavarzi F., 2014. Genetic diversity and geographical differentiation of Iranian landrace, cultivars, and exotic chickpea lines as revealed by morphological and microsatellite markers. Physiology and Molecular Biology of Plants 20(2): 225-233.

Hayden M., Nguyen T., Waterman A., Chalmers K., 2008. Multiplex-Ready PCR: A new method for multiplexed SSR and SNP genotyping. BMC Genomics 9: 80.

Kaiser W.J., 1997. Inter- and international spread of Ascochyta pathogens of chickpea, faba bean, and lentil. Canadian Journal of Plant Pathology 19: 215-224.

Kanouni H., Taleei A., Okhovat M., 2011. Ascochyta blight (Ascochyta rabiei (Pass.) Lab.) of chickpea (Cicer arietinum L.): Breeding strategies for resistance. International Journal of Plant Breeding \& Genetics 5(1): 1-22.

Karami E., Talebi R., Kharkesh M., Saidi A., 2015. A linkage map of chickpea (Cicer arietinum L.) based on population from ilc3279 $\times$ ilc588 crosses: location of genes for time to flowering, seed size and plant height. Genetika 47: 253-263.

Keller S.M., McDermott J.M., Pettway R.E., Wolfe M.S., McDonald B.A., 1997. Gene flow and sexual reproduction in the wheat glume blotch pathogen Phaeosphaeria nodorum (anamorph: Stagonospora nodorum). Phytopathology 87: 353-358.

Kimurto P. K., Towett B. K., Mulwa R. S., Njogu N., Jeptanui L. J., Rao G. N., Silim S., Kaloki P., Korir P., Macharia J. K., 2013. Evaluation of chickpea genotypes for resistance to ascochyta blight (Ascochyta rabiei) disease in the dry highlands of Kenya. Phytopathologia Mediterranea 52: 212-221.

McDonald B. A., Linde C., 2002. Pathogen population genetics, evolutionary potential and durable resistance. Annual Review of Phytopathology 40: 349-379.

McDonald B.A., 1997. The population genetics of fungi: Tools and techniques. Phytopathology 87: 448-453.

Mehrabi R., Makhdoomi A., Jafar-Aghaie M., 2015. Identification of new sources of resistance to septoria tritici blotch caused by Zymoseptoria tritici. Journal of Phytopathology 163(2): 84-90.

Merga B., Haji J., Fatih Y., 2019. Economic importance of chickpea: Production, value, and world trade. Cogent Food \& Agriculture 5(1): 1615718.

Montakhabi M.K., Shahidi Bonjar G.H., Talebi R., 2020. mating type profiling and SSR-based genetic diversity analysis of Iranian Fusarium oxysporum f. sp. ciceris causing wilt in chickpea. International Journal of Agriculture \& Biology 23: 1101-1106.

Morjane H., Geistlinger J., Harrabi M., Weising K., Kahl G., 1994. Oligonucleotide fingerprinting detects genetic diversity among Ascochyta rabiei isolates from a single chickpea field in Tunisia. Current Genetics 26: 191-197.

Nourollahi K., Javannikkhah M., Naghavi M. R., Lichtenzveig J., Okhovat M., ... Ellwood S. R., 2011. Genetic diversity and population structure of Ascochyta rabiei from the western Iranian Ilam and Kermanshah provinces using MAT and SSR markers. Mycological progress 10: 1-7.

Ozer G., Bayraktar H., Dolar F.S., 2012. Genetic diversity and mating-type distribution within populations of Ascochyta rabiei in Turkey. Indian Journal of Agricultural Sciences 82(1): 3-7.

Peakall R., Smouse P.E., 2006. GenAlEx 6: genetic analysis in Excel. Population genetic software for teaching and research. Molecular Ecology Notes 6: 288-295.

Pande S., Sharma M., Gaur P.M., Tripathi S., Kaur L., ...Siddique K.H.M., 2011. Development of screening techniques and identification of new sources of 
resistance to Ascochyta blight disease of chickpea. Australian Plant Pathology 40(2): 149-156.

Pande S., Siddique K.H.M., Kishore G.K., Baaya B., Gaur P.M., ...Crouch J.H., 2005. Ascochyta blight of chickpea (Cicer arietinum L.): a review of biology, pathogenicity, and disease management. Australian Journal of Agricultural Research 56: 317-332.

Peever T. L., Salimath S., Su G., Kaiser W. J., Muehlbauer F. J., 2004. Historical and contemporary multilocus population structure of Ascochyta rabiei (teleomorph: Didymella rabiei) in the Pacific Northwest of the United States. Molecular Ecology 13: 291-309.

Perrier X., Flori A., Bonnot F., 2003. Data analysis methods. In: Hamon P., Seguin M., Perrier X., Glaszmann J.C., Ed., Genetic diversity of cultivated tropical plants. Enfield, Science Publishers, Montpellier, pp 43-76.

Phan H.T.T., Ford R., Taylor P.W.J., 2003a. Mapping the mating type locus of Ascochyta rabiei, the causal agent of Ascochyta blight of chickpea. Molecular Plant Pathology 4: 373-381.

Phan H.T.T., Ford R., Taylor P.W.J., 2003b. Population structure of Ascochyta rabiei in Australia based on STMS fingerprints. Fungal Diversity 13: 111-129.

Pritchard J.K., Stephens M., Donnelly P., 2000. Inference of population structure using multilocus genotype data. Genetics 155: 945-959.

Rhaiem A., Cherif M., Dyer P. S., Peever T. L., 2007. Distribution of mating types and genetic diversity of Ascochyta rabiei populations in Tunisia revealed by mating-type- specific PCR and random amplified polymorphic DNA markers. Journal of Phytopathology 155: 596-605.

Santra D. K., Singh G., Kaiser W. J., Gupta V. S., Ranjekar P. K., Muehlbauer F. J., 2001. Molecular analysis of Ascochyta rabiei (Pass.) Labr., the pathogen of ascochyta blight in chickpea. Theoretical and Applied Genetics 102: 676-682.

Singh K.B., Reddy M.V., 1996. Improving chickpea yield by incorporating resistance to ascochyta blight. Theoretical and Applied Genetics 92: 509-515.

Talebi R., Naji A.M., Fayaz F., 2008. Geographical patterns of genetic diversity in cultivated chickpea (Cicer arietinum L.) characterized by amplified fragment length polymorphism. Plant Soil Environment 54(10): 447-452.

Taylor P. W. J., Ford R., 2007. Diagnostics, genetic diversity and pathogenic variation of ascochyta blight of cool season food and feed legumes. European Journal of Plant Pathology 119: 127-133.

Trapero-Casas A., Kaiser W.J., 1992. Development of Didymella rabiei, the teleomorph of Ascochyta rabiei, on chickpea straw. Phytopathology 82: 1261-1266
Turkkan M., Dolar F.S., 2009. Determination of pathogenic variability of Didymella rabiei, the agent of ascochyta blight of chickpea in Turkey. Turkish Journal of Agriculture \& Forestry 33: 585-591

Vafaei S.H., Rezaee S., Moghadam A., Zamanizadeh H.R., 2016. Virulence diversity of Ascochyta rabiei the causal agent of Ascochyta blight of chickpea in the western provinces of Iran. Archive of Phytopathology and Plant Protection 48: 921-930.

VanDer Maesen L.J.G., 1987. Origin, history and taxonomy of chickpea. In: The chickpea. Saxena, M.C. and Singh, K.B. (eds). CAB International Publications, Oxford, UK, 11-34.

Varshney R., Pande S., Kannan S., Mahendar T., Sharma M., ...Hoisington D., 2009. Assessment and comparison of AFLP and SSR based molecular genetic diversity in Indian isolates of Ascochyta rabiei, a causal agent of ascochyta blight in chickpea (Cicer arietinum L.). Mycological Progress 8: 87-97

Varshney R.K., Song C., Saxena R.K., Azam S., Yu S., Sharpe A.G., 2013. Draft genome sequence of chickpea (Cicer arietinum) provides a resource for trait improvement. Nature Biotechnology 31: 240-246.

Weising K., Kaemmer D., Epplen J. T., Weigand F., Saxena M., Kahl, G., 1991. DNA fingerprinting of Ascochyta rabiei with synthetic oligodeoxynucleotides. Current Genetics 19: 483-489.

Younessi H., Okhovat S. M., Hejaroud G. A., Zad S. J., Taleei A. R., Zamani, M. R., 2004. Virulence variability of Ascochyta rabiei isolates on chickpea cultivars in Kermanshah province. Iranian Journal of Plant Pathology 39: 213-228.

Zhan J., Kema G.H., Waalwijk C., McDonald B.A., 2002. Distribution of mating type alleles in the wheat pathogen Mycosphaerella graminicola over spatial scales from lesions to continents. Fungal Genetics and Biology 36: 128-136. 